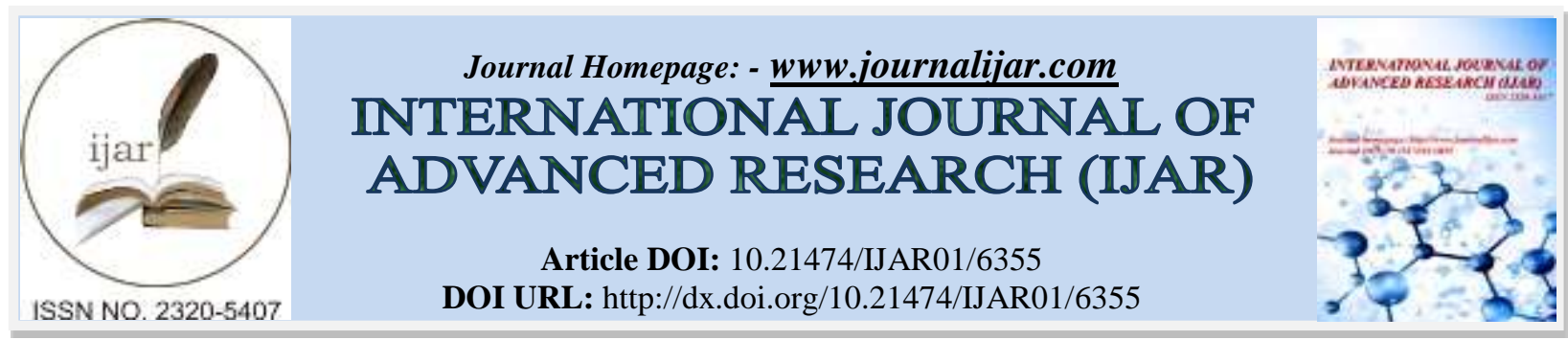

RESEARCH ARTICLE

\title{
MAGNETIC DISC TYPE FEEDER.
}

\section{Charanjeev Mehndiratta ${ }^{1}$, Himank Ambashta ${ }^{1}$, Lakshay Sachdeva $^{1}$ and Nitin Waghmare ${ }^{2}$.}

1. Dept. of Mechanical Engineering, Manav Rachna International University, Haryana, India.

2. Assistant Professor, Manav Rachna International University, Haryana, India.

\section{Manuscript Info}

Manuscript History

Received: 02 September 2017

Final Accepted: 04 October 2017

Published: November 2017

Key words:-

Feeder, no. of bolts, Chute.

\begin{abstract}
In contemporary automated assemblage lines, feeding of engineering parts in the accurate positioning manner is one of the important processes and part feeders are used in the automated feeding and correct placing of the components. In feeder, parts are stored in bulk and are sent in discrete manner to the machine to which it is attached. The overall function of the feeder is to provide a steady stream of parts, all in a specified orientation.

Part feeders are broadly classified as universal and customized. Universal feeders are vibratory bowl type feeder and customized feeders are made according to customer needs. Customized feeders are of many types such as rotary hook feeder, pneumatic reciprocating feeder, centerboard hopper feeder, scoop wheel feeder etc.

The purpose of this analysis is to develop the magnetic disc type feeder to feed industrial components like bolt. In this feeder, parts are fed into the hopper and get attracted by magnets present in the slots provided on the disc. The disc rotates and parts move on to the chute attached to the disc in a required orientation.

Furthermore, the feeding process is automated with the help of sensors to get minimum number of parts at feeding site to avoid overcrowding and also a counting facility is provided to count the number of bolts passing through.
\end{abstract}

Copy Right, IJAR, 2017,. All rights reserved.

\section{Introduction:-}

Automation of assembly line is necessary for any manufacturing system. As in same time and increases the production than work done my manpower in that time. Feeders are important part of automation of assembly lines. An assembly line consist of an arrangement of workforces, machines, and other equipment's. And the product being manufactured passes through a procedure to procedure until the product is manufactured.

Feeders are designed to provide a uninterrupted feed rate to the assembly lines. Feed rate should be unhindered and parts must be oriented before being fed to machine. The finished product obtained at the end will comprise of parts added to other parts. In the automated feeders, the feed rate and the machine rate should be steady such that the condition of starvation or saturation of the parts is averted.

The present work aims at fabricating, experimenting and analyzing a magnetic disk type feeder under different values of the No. of bolts, speed and number of magnets 


\section{A. General Considerations}

Certain general considerations that need to be taken are:

- While designing and testing of the feeders, feed rate should be appropriate so that it does not restrain the output of the feeder. As feeder is connected to a machine and is feeding parts so it becomes very important that feed rate should be right otherwise it can cause in working of machine and can increase ideal time which is not desired. This is known as the unhindered feed rate. The unhindered feed rate should always be greater than the rate at which a machine is working.

- Some feeders can feed different types of parts at the same time as others are only able to feed only one type of part.

\section{Classification:-}

Vibratory feeders are used in industry, especially for a broad range of bulk materials, depending upon the range of particle sizes, and can be used for abrasive materials. While vibratory feeder always remains the primary choice for general requirements but it has certain limitations as there are designs where the special features like head part or abrasive materials are used:

- $\quad$ Reciprocating feeders

- Rotary feeders

- Belt feeders

Selection of Non- vibratory rotary feeder is done for our research analysis. [1]

\section{Principle Of Working:-}

The whole setup is installed on a wooden based system. The rotating disc forms the important part of the system in which magnets are placed on the back side of disc. Slots are provided for the placing of the magnets. A semi spherical bowl called hopper is provided for feeding of the components. A chute is made for components to come out of the feeder and a grooved passage is provided for the targeted orientation of the system. Parts are fed in the hemispherical hopper. When a suitable power is supplied to the motor, disc rotates and parts get attracted towards the disc because of magnetic action. For steady path and orientation of the components, a chute and passage is provided. Parts go to the chute and move towards the passage in which a groove is provided for the orientation of the part [2][3].

To automate the feeding process, IR sensor [4] is used to count the number of bolts required at feeding site and a counting facility is provided to count number of bolts passing through chute. Arduino [5] was programed for LCD to show no. of bolts and was connected to IR sensor. For fulfilling of this purpose, IR sensor is used to sense the bolts passing through chute, LCD will display the number of bolts that has passed. Solenoid piston is there at the end of chute and it operates the gate. The gate is closed when required count is obtained and dc motor also stops. This is done to avoid overcrowding. There was also a reset button to reset the count to zero

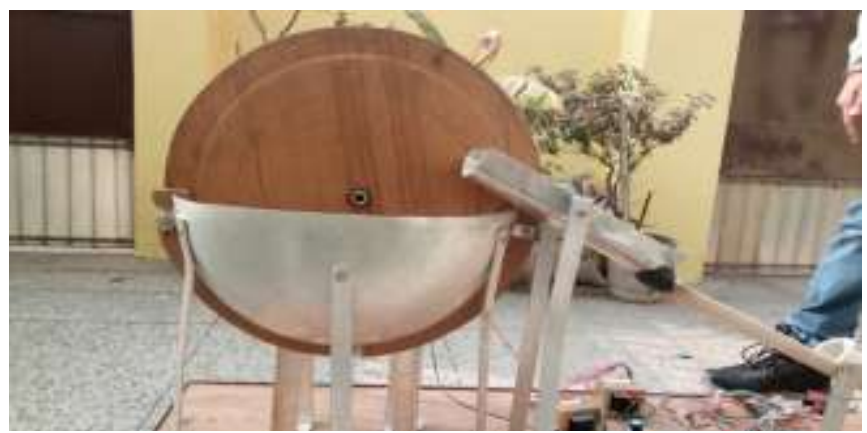

Figure 1:- Front View 


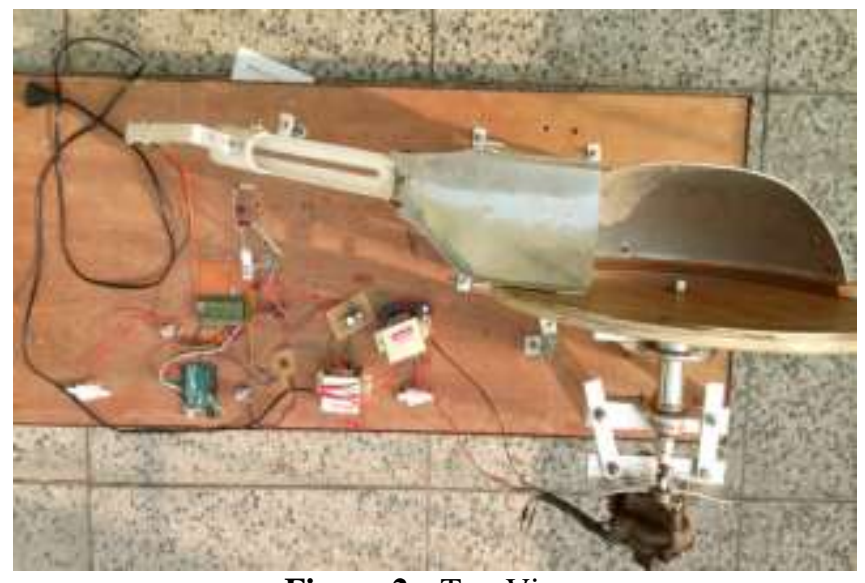

Figure 2:- Top View

\section{Driving Mechanism:-}

For rotary motion, electrical driver is used in magnetic feeder to deliver a high torque at relatively lower speed followed by speed controller. A geared DC motor is selected since it matches the required features. The drive is connected directly to the magnetic disc with the help of the motor and entire assembly is mounted on a raised platform. It is fixed rigidly on a solid wooden base.

\section{Experimental Work:-}

The procedure is carried out by taking one factor variable at a time. To study the effect of no. of bolts the length of the bolts is kept constant and the experiment is carried out by varying speed of rotation with respect to number of bolts and results are obtained. For performing the experiment, component length and number of magnets is fixed, and feed rate is calculated by varying no. of bolts with respect to speed of rotation of disc. This is done to study the effect of no. of bolts on feed rate. To learn the effect of number of magnets, part length is kept constant and feed rate is obtained by varying number of magnets with respect to no. of bolts. [6].

Our analysis has been noted down in accordance of three parameters which are as follows: -

- No. of bolts

- Motor's Speed

- Number of magnets

\section{A. Range of Parameters}

- No. of bolts in the feeder is varied from 100 to 200.

- Speed of the motor is important parameter and it fluctuates from least of $10 \mathrm{rpm}$ to a maximum of $22 \mathrm{rpm}$.

- $\quad$ Number of magnet used are 4, 8 and 12. [7]

Table 1:- List Of The Specifications Of The Feeder

\begin{tabular}{|l|l|l|}
\hline S.NO. & Parts & SPECIFICATIONS \\
\hline 1. & BOLT & $\begin{array}{l}\text { Length }-1 \text { inch } \\
\text { Diameter - } 1 / 4 \text { inch } \\
\text { Material used - carbon steel } \\
\text { Thread Pitch - 20tpi }\end{array}$ \\
\hline 2. & HOOPER & $\begin{array}{l}\text { Diameter }-40 \mathrm{~cm} \\
\text { Material used - Aluminum }\end{array}$ \\
\hline 3. & DISC & $\begin{array}{l}\text { Diameter }-40 \mathrm{~cm} \\
\text { Material used -Wood }\end{array}$ \\
\hline 4. & DRIVE & DC geared motor \\
\hline 5. & CHUTE & $\begin{array}{l}\text { Length }-40 \mathrm{~cm} \\
\text { Material Used: Aluminum }\end{array}$ \\
\hline 6. & AREA OF BASE & $114 \mathrm{~cm}$ x $46 \mathrm{~cm}$ \\
\hline 7. & MAGNETS & Diameter: $4.8 \mathrm{~cm}$ \\
\hline
\end{tabular}


Observations

Table 2:- table containing different parameters (no. Of bolts, speed and number of magnets)

\begin{tabular}{|c|c|c|c|c|}
\hline No. of bolts & Speed (rpm) & 12 magnets & 8 magnets & 4 magnets \\
\hline \multirow[t]{4}{*}{200} & 10 & 19 & 20 & 16 \\
\hline & 14 & 31 & 25 & 19 \\
\hline & 18 & 75 & 37 & 21 \\
\hline & 22 & 80 & 48 & 29 \\
\hline \multirow[t]{4}{*}{150} & 10 & 22 & 32 & 18 \\
\hline & 14 & 60 & 36 & 19 \\
\hline & 18 & 68 & 54 & 28 \\
\hline & 22 & 78 & 59 & 32 \\
\hline \multirow[t]{4}{*}{100} & 10 & 19 & 31 & 19 \\
\hline & 14 & 31 & 32 & 19 \\
\hline & 18 & 51 & 39 & 35 \\
\hline & 22 & 63 & 55 & 38 \\
\hline
\end{tabular}

A. Effect of RPM Vs Feed Rate at PP 200

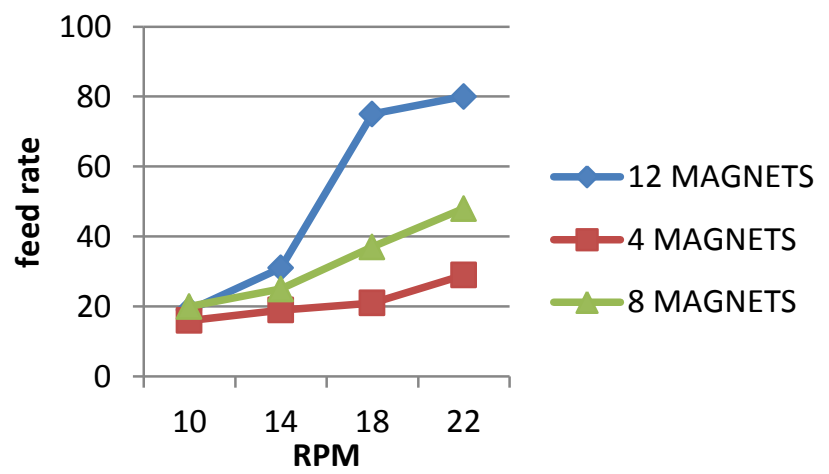

Graph 1:- Feed Rate Vs no. of bolts 200 at different RPM

From the graph 1, it is depicted that the no. of bolts is kept at 200 which marks the feed rate, while changing other constraints, such that the graph of No. of bolts v/s Feed rate surges to a highest value when 12 magnets are used. We need to recognize the role the number of bolts should play in the process of parts that are chosen by the Magnets. It was observed that the Hooper is pushed to another side because of the the tumbling agitation of parts. In the presence of the magnet, the pieces are pushed are then picked by the magnets. Later, they position themselves when they fall on chute. Chute has groove which runs across the length. Appropriate feed rate is hard to obtain as the parts fail to orient themselves Also, is it observed that when RPM is between 14 to 18, there is the prominent increase in feed rate. Furthermore, in increasing the RPM from 18 to 22, we note that there isn't much increase in the feed rate because of the no. of bolts, as there is less amount of time for disc to pick bolts. 


\section{B. Effect of RPM Vs Feed Rate at PP 150}

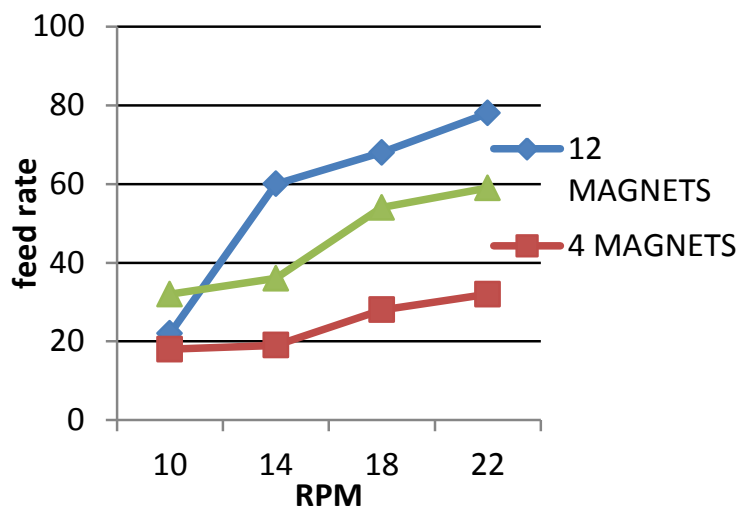

Graph 2:- Feed Rate Vs No. of bolts is 150 at different RPM

From graph 2, it is observed that the no. of bolts is kept at 150 in order to observe the change in the feed rate, while changing other parameters, such that the graph of No. of bolts v/s Feed rate increases to a maximum value. Also, we observed that there is the proportionate increase in fed rate with respect to the RPM of magnetic disc. It physically signifies that the magnets are picking the parts effectively, the parts are able to orient themselves properly due to which IR sensor isn't finding difficulties in the counting.

C. Effect of RPM Vs Feed Rate at PP 100

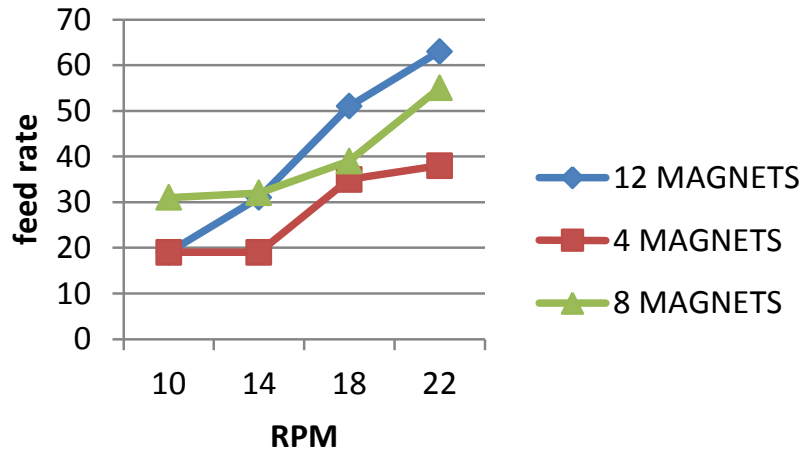

Graph 3:- Feed Rate Vs No. of bolts is 100 at different RPM

From Graph 3, the no. of bolts is kept at 100, we observed that feed rate is increasing linearly while using of 12 magnets which implies that the parts are sticking to the magnets appropriately and able to orient themselves properly. Whereas on the application of 8 magnets and 4 magnets, graph shows the slightly exponential and step linear nature respectively.

\section{Conclusion:-}

In this, we have improved the part feed system by using Magnetic type disc feeder. This approach is based on the design and experimental setup by our team to complete the task more efficiently the optimum results are as follows.

Table 3:- Optimum Results

\begin{tabular}{|l|l|}
\hline PARAMETERS & VALUES \\
\hline No. of bolts & 100 \\
\hline Number of magnet & 12 \\
\hline Speed of motor & $22 \mathrm{rpm}$ \\
\hline
\end{tabular}




\section{Acknowledgement:-}

We would like to show gratitude Mr. Nitin Wagmare, Assistant Professor, FET, Department of Mechanical Engineering, Manav Rachna International University, for supervision.

\section{References:-}

1. Sheetal Bhagat, Tanushi Pandey, Vishesh Garg and Pradeep Khanna, "Design, Fabrication and Analysis of Vibratory Feeder" IJRMET Vol. 4, Issue 1, Nov 2013 - April 2014, ISSN: 2249-5762 (Online) | ISSN: 22495770 (Print)

2. Ritika Punn, Shruti Bansal, Sakshi Jain, Meenakshi Goel and Pradeep Khanna, "Graphical Modelling Approach for Optimization of a Rotary Hook Feeder" IJRMET Vol. 3, Issue 2, May - Oct 2013, ISSN: 22495762 (Online) ISSN: 2249-5770 (Print).

3. Geoffrey Boothroyd, Peter Dewhurst and Winston A. Knight, "Product Design for Manufacture and Assembly", Standards media, Third Edition, ISBN-10: 1420089277, ISBN-13: 978-1420089271

4. Antonio Rogalski, "Infrared Detectors", CRC Press; 2 edition, November 15, 2010, ISBN-10: 142007671X, ISBN-13: 978-142007671

5. Massimo Banzi, "Getting Started with Arduino", Make; Ill edition, ASIN: B008SMKPW0

6. Geoffrey Boothroyd, "Assembly Automation and Product Design", CRC Press, second edition, 2005, ISBN10: 1574446436, ISBN-13: 978-1574446432

7. Singh S.P., Ghosh S., Khanna P., Tanwar A, "Mathematical performance analysis of rotary fork hopper feeder", Proceedings of 2009 IEEE Student Conference on Research and Development (SCORED), UPM Serdang, Malaysia, Nov. 2009. 